\title{
Material-Technology Index to evaluate micro-EDM drilling process
}

\author{
G. D’Urso ${ }^{1 *}$, C. Ravasio ${ }^{2}$ \\ I * University of Bergamo - DIGIP - Via Pasubio 7b, 24044 Dalmine (BG) - Italy - gianluca.d-urso@unibg.it \\ ${ }^{2}$ University of Bergamo - DIGIP - Via Pasubio 7b, 24044 Dalmine (BG) - Italy - chiara.ravasio@unibg.it \\ *Corresponding author
}

\begin{abstract}
This research aims to study the influence of the process parameters and the thermal and electrical properties of workpiece and electrode materials on the performance of micro-EDM drilling. An experimental campaign was carried out using different workpiece materials such as stainless steel, tungsten carbide and aluminum and as electrode materials tungsten carbide and brass. Material Removal Rate (MRR) and Tool Wear Ratio (TWR) were assumed as performance indicators. The geometrical characteristics of micro-holes were evaluated by taking into account Diametral Overcut (DOC) and Taper Rate (TR). A “Material-Technology Index" (MTI), taking into account EDM process parameters, electrical and thermal properties of workpiece and electrode materials, was defined for each indicator. The effect of the MT indexes on the process performance and geometrical indicators was studied and proper fitting equations, having satisfactory coefficients of determination, were used to summarize the analyzed behaviors. Finally, a surface integrity analysis was carried out on the micro holes obtained in different conditions.
\end{abstract}

Keywords: micro-EDM drilling, material-technology index, process performance, stainless steel, tungsten carbide, aluminium.

\section{Introduction}

Over the past several years there has been an increased interest in micro machining technology that has captured the imagination of every manufacturing and industry segment; from aerospace, medical appliance and automotive world, the potential for product miniaturization continues to grow giving rise to numerous technical challenges $[1,2]$. In response to this continued miniaturization, companies are developing new technologies to meet the unique challenges established by micro manufacturing and must develop appropriate machining systems to support this growth. 
Electrical discharge machining (EDM) is considered an attractive solution for the manufacturing of microcomponents [3]. The material is removed by a succession of electrical discharges which occur between the electrode and the workpiece, submersed in a dielectric fluid such as kerosene or deionized water. Since EDM is a contact-less process, it is suitable for the machining of hard and high-strength materials, otherwise considered "difficult to cut" with conventional technologies, and micro-parts without distortion due to the possible physical forces [4]. Micro-EDM is one of the most effective methods used to carry out micro deep holes in metal used for several purposes in a lot of products, such as inkjet printer nozzles, spinner holes, turbine blades cooling channels, diesel fuel injection nozzles and drug delivery orifices [5]. The use of the proper process parameters is essential to achieve high material removal rate. Literature reports several papers that investigate the influence of the process parameters on the machining performance. For example, micro electro discharge drilling of a titanium super alloy was investigated in [6], showing that machining performance is mostly affected by peak current and pulse on time. Small deep hole drilling of Inconel 718, using EDM technology with a pure electrolytic copper electrode, was carried out in [7] varying peak current, pulse on time, duty factor and electrode speed. The results revealed that MRR is more influenced by peak current, duty factor and electrode rotation. As regard the roughness, the workpiece was cut into equal slices using WEDM process. Then, surface roughness was measured in the slices using an instrument fitted with a small hole detector probe attachment to measure surface roughness inside the small holes. The depth average surface roughness (mean of the obtained roughness of the slices) was revealed to be strongly influenced by peak current and pulse on time.

In [8] the effects of variation of discharge energy density on the process was studied asserting that the discharge energy can be used as a criterion in determining performance such as MRR, electrode wear rate and surface quality.

Not only process parameters can affect the final output but also the tool and the workpiece material properties. Thermal and electrical properties play a vital role in determining the EDM machinability of the workpiece materials and how efficiently the material can be heated up, vaporized and cooled down. In [9] a comparison between $\mathrm{Ti}-6 \mathrm{Al}-4 \mathrm{~V}$ and a common steel material was made. Titanium alloys have relatively higher melting temperature, lower thermal conductivity and higher electrical resistivity when compared to other commonly EDMed materials. While the EDMing strategy for steel materials is well-known and a desired productivity and/or quality can be achieved by adjusting the discharge settings in a known method, for titanium alloys, this same strategy cannot be applied due to considerably different material properties. A study for the definition of an 
easier machining approach by EDM was presented in [10], where the total energy of discharge pulses required to machine different workpiece materials was calculated. Electrical resistivity, thermal conductivity and melting point of workpiece involve the electric current transfer to create the discharge pulse. Lower electrical resistivity results in a better transfer of electric current. Several workpiece materials were used and a relation between the discharge pulse number and the product among electrical resistivity, thermal conductivity and melting point of the workpiece was found. From the point of view of tool electrode, an index to evaluate the wear resistance of the tool was presented in [11]. The volumetric wear ratio of the electrode becomes small for the electrode material with high boiling point, high melting point and high thermal conductivity. Moreover, the authors found that the boiling point of the electrode material plays an important role in wear mechanism of micro-EDM, since high surface temperature and high energy density correspond to small discharge spot. This paper proposed an index to evaluate the electrode performance. The index was identified by $\lambda \rho c T_{m c} T_{b c}$ where $\lambda$ was thermal conductivity, $\rho$ density, c specific heat, $T_{m c}$ melting point and $T_{b c}$ boiling point of electrode materials. The effect of workpiece hardness on EDM performance was studied in [12]. By a mathematical model, it was demonstrated that the MRR and the workpiece surface roughness are directly dependent on the workpiece hardness. As regard the workpiece microstructure, in [13] it was demonstrated the influence of material microstructure on the machining performance of EDM drilling micro holes. In fact, when a feature downscales to the order of micrometer, the material is not homogeneous and therefore performance are different as a function of the location.

In [14] a study of the in progress material removal rate (MRR) and tool wear ratio (TWR) during the drilling process of stainless steel plates was performed. Some mathematical laws governing the relation between process parameters and performance indexes were defined. Two technological windows representing TWR and MRR as a function of the hole depth, for different electrode materials, were obtained.

A micro-EDM machinability comparison between difficult to cut Ti-6Al-4V and soft brass was made in [15]. The machinability of the two materials was evaluated based on the quality of the micro-features in terms of dimensional accuracy, surface finishing, and profile accuracy of the features. In [16] an investigation on the influence of different electrodes materials and power discharge on both the process performance and the dimensional characteristics of micro-EDM stainless steel holes was performed. Tubular electrodes made of three different materials (tungsten carbide, brass and copper) were used. The authors found that the choice of electrode material has effects on the process performance and the use of power discharge can be considered as a valid method for representing the effects of process parameters on the EDM performance. 
The effect on the performance of electrical resistivity, thermal conductivity and melting point of both electrode and workpiece materials was studied in [17]. A process index based on both process parameters and electrode material properties was defined. This index fits with a good coefficient of determination all the process performance and geometric indicators for the considered workpiece materials.

Aim of this paper is to set up an index able to take into account both the process parameters and the properties of workpiece and electrode materials of micro-EDM drilling. Micro holes were executed on stainless steel (AISI 304), tungsten carbide and aluminum AA 6062 plates having a thickness equal to $3 \mathrm{~mm}$. Two electrode materials, brass and tungsten carbide, having the diameter equal to $0.3 \mathrm{~mm}$ were used. A "Material and Technological Index" (MTI) for each indicator was defined taking into account EDM process parameters and electrical and thermal properties of workpiece and electrode material. The effect of the MTI on both the process performance and the geometrical characteristics of micro holes was studied and described by some mathematical laws.

\section{Experimental set up}

A Sarix SX-200 micro-EDM machine was used in the experimental campaign. The micro-holes were executed on stainless steel (AISI 304), tungsten carbide (WC94Co6) and aluminium (AA6062) plates having a thickness equal to $3 \mathrm{~mm}$. Table 1 reports the properties of the workpiece materials. Two different electrode materials, brass and tungsten carbide, were used because of their different thermal, physical and electrical characteristics (Table 2). The electrodes were tubular, with outer and inner diameters equal to $0.3 \mathrm{~mm}$ and $0.12 \mathrm{~mm}$ respectively. Hydrocarbon oil was used as dielectric and an internal electrode washing pressure equal to 6 bar was set.

Table 1. Physical properties of workpiece materials.

\begin{tabular}{lccc}
\hline Physical Property & AISI 304 & $\begin{array}{c}\text { Tungsten carbide } \\
\text { WC94Co6 }\end{array}$ & AA 6062 \\
\hline Density $\left[\mathrm{g} / \mathrm{cm}^{3}\right]$ & 8 & 14.8 & 2.7 \\
Melting temperature $\left(\mathrm{T}_{\mathrm{w}}\right)\left[{ }^{\circ} \mathrm{C}\right]$ & 1455 & 2867 & 651.7 \\
Electrical resistivity $\left(\rho_{\mathrm{w}}\right)[\Omega \mathrm{cm}]$ & $7.2 \cdot 10^{-5}$ & $20 \cdot 10^{-6}$ & $3.66 \cdot 10^{-6}$ \\
Thermal conductivity $\left(\mathrm{k}_{\mathrm{w}}\right)[\mathrm{W} / \mathrm{mK}]$ & 16.2 & 70 & 180 \\
Specific heat $\left[\mathrm{J} /\left(\mathrm{g}^{\circ} \mathrm{C}\right)\right]$ & 0.5 & 0.3 & 0.9 \\
\hline
\end{tabular}

*Source: www.matweb.com 
A certain number of process parameters was kept constant for each combination workpiece-electrode material, as reported in Table 3. As regard energy parameter, it establishes the shape of the pulse; width is the time the transistor remains active. Gain is a parameter that controls the gain of the reaction block. Gap is a value proportional to the distance between the electrode and the workpiece during the erosion and regulation identifies a certain regulation management algorithm defined by the machine manufacturer. In [18] the pulse characterisation of a Sarix machine was executed thorough the comparison of voltage and current waveforms varying input parameters. Anyway, it can be noted that the measurements of voltage and current during the discharge always refer to specific conditions and therefore are not extendible to general conditions.

Table 2. Physical properties of electrode materials.

\begin{tabular}{lcc}
\hline Physical Property & Brass C26800 & Tungsten carbide \\
\hline Density $\left[\mathrm{g} / \mathrm{cm}^{3}\right]$ & 8.47 & WC94Co6 \\
Melting temperature $\left(\mathrm{T}_{\mathrm{el}}\right)\left[{ }^{\circ} \mathrm{C}\right]$ & $905-930$ & 2867 \\
Electrical Resistivity $\left(\rho_{\mathrm{el}}\right)[\Omega \mathrm{cm}]$ & $6.63 \cdot 10^{-6}$ & $20 \cdot 10^{-6}$ \\
Thermal conductivity $\left(\mathrm{k}_{\mathrm{el}}\right)[\mathrm{W} / \mathrm{mK}]$ & 121 & 70 \\
Specific heat $\left[\mathrm{J} /\left(\mathrm{g}^{\circ} \mathrm{C}\right)\right]$ & 0.38 & 0.3 \\
\hline
\end{tabular}

*Source: www.matweb.com

Table 3. Fixed process parameters.

\begin{tabular}{|c|c|c|c|c|c|c|}
\hline \multirow{2}{*}{$\begin{array}{l}\text { Tool type } \\
\text { Workpiece }\end{array}$} & \multicolumn{3}{|c|}{ Brass C26800 } & \multicolumn{3}{|c|}{ Tungsten carbide WC94Co6 } \\
\hline & AISI 304 & WC & AA 6062 & AISI 304 & WC & AA 6062 \\
\hline Energy & 365 & 365 & 365 & 365 & 365 & 365 \\
\hline Polarity & - (neg) & - (neg) & - (neg) & - (neg) & - (neg) & - (neg) \\
\hline Width $[\mu \mathrm{s}]$ & 4 & 3.8 & 3 & 4.7 & 5 & 3 \\
\hline Gain & 120 & 120 & 15 & 50 & 40 & 15 \\
\hline Gap [\%] & 50 & 5 & 40 & 70 & 20 & 40 \\
\hline Rot. speed & $100 \%$ & $100 \%$ & $100 \%$ & $100 \%$ & $100 \%$ & $100 \%$ \\
\hline Regulation & 03-01 & 03-01 & 03-01 & 03-01 & 03-01 & 03-01 \\
\hline
\end{tabular}


Peak current $(I)$, voltage $(V)$ and frequency $(F)$ were varied (Table 4). In the Sarix EDM machine, the measurement unit of peak current is expressed as an index and there is not a direct correlation with the actual value of current expressed in Ampere.

Table 4. Combination of Technologies.

\begin{tabular}{|c|c|c|c|c|c|c|}
\hline Tool & & $\mathrm{TC}$ & & & Brass & \\
\hline Tecno & I [index] & $\mathrm{V}$ [V] & $\mathrm{F}[\mathrm{kHz}]$ & I & $\mathrm{V}[\mathrm{V}]$ & $\mathrm{F}[\mathrm{kH}]$ \\
\hline \multicolumn{7}{|c|}{ AISI 304} \\
\hline 1 & 40 & 110 & 110 & 65 & 110 & 130 \\
\hline 2 & 40 & 93 & 110 & 65 & 135 & 113 \\
\hline 3 & 40 & 127 & 110 & 65 & 135 & 130 \\
\hline 4 & 40 & 110 & 127 & 65 & 135 & 147 \\
\hline 5 & 40 & 110 & 93 & 40 & 135 & 130 \\
\hline 6 & 50 & 120 & 100 & 50 & 120 & 140 \\
\hline 7 & 50 & 100 & 120 & 50 & 120 & 120 \\
\hline 8 & 50 & 120 & 120 & 50 & 150 & 140 \\
\hline 9 & 50 & 100 & 100 & 80 & 120 & 140 \\
\hline 10 & 30 & 100 & 100 & 80 & 150 & 140 \\
\hline 11 & 30 & 120 & 120 & 80 & 150 & 120 \\
\hline 12 & 30 & 100 & 120 & 90 & 135 & 130 \\
\hline 13 & 30 & 120 & 100 & 80 & 120 & 120 \\
\hline 14 & 57 & 110 & 110 & 50 & 150 & 120 \\
\hline 15 & 23 & 110 & 110 & 65 & 110 & 130 \\
\hline \multicolumn{7}{|c|}{ Tungsten carbide (WC) } \\
\hline 1 & 40 & 110 & 83 & 26 & 120 & 130 \\
\hline 2 & 30 & 100 & 90 & 40 & 100 & 110 \\
\hline 3 & 50 & 100 & 90 & 40 & 140 & 110 \\
\hline 4 & 30 & 120 & 90 & 40 & 100 & 150 \\
\hline 5 & 50 & 120 & 90 & 40 & 140 & 150 \\
\hline 6 & 40 & 93 & 100 & 60 & 120 & 96 \\
\hline
\end{tabular}




\begin{tabular}{|c|c|c|c|c|c|c|}
\hline 7 & 23 & 110 & 100 & 60 & 86 & 130 \\
\hline 8 & 40 & 110 & 100 & 60 & 120 & 130 \\
\hline 9 & 57 & 110 & 100 & 60 & 154 & 130 \\
\hline 10 & 40 & 127 & 100 & 60 & 120 & 160 \\
\hline 11 & 30 & 100 & 110 & 80 & 100 & 110 \\
\hline 12 & 50 & 100 & 110 & 80 & 140 & 110 \\
\hline 13 & 30 & 120 & 110 & 80 & 100 & 150 \\
\hline 14 & 50 & 120 & 110 & 80 & 140 & 150 \\
\hline 15 & 40 & 110 & 117 & 94 & 120 & 130 \\
\hline \multicolumn{7}{|c|}{ AA 6062} \\
\hline 1 & 140 & 130 & 110 & 140 & 130 & 110 \\
\hline 2 & 100 & 130 & 90 & 100 & 130 & 90 \\
\hline 3 & 100 & 130 & 110 & 100 & 130 & 110 \\
\hline 4 & 100 & 100 & 90 & 100 & 100 & 90 \\
\hline 5 & 140 & 130 & 90 & 140 & 130 & 90 \\
\hline 6 & 120 & 115 & 83 & 120 & 115 & 83 \\
\hline 7 & 120 & 115 & 117 & 120 & 115 & 117 \\
\hline 8 & 140 & 100 & 90 & 140 & 100 & 90 \\
\hline 9 & 86 & 115 & 100 & 86 & 115 & 100 \\
\hline 10 & 100 & 100 & 110 & 100 & 100 & 110 \\
\hline 11 & 120 & 90 & 100 & 120 & 90 & 100 \\
\hline 12 & 140 & 100 & 110 & 140 & 100 & 110 \\
\hline 13 & 120 & 140 & 100 & 120 & 140 & 100 \\
\hline 14 & 120 & 115 & 100 & 120 & 115 & 100 \\
\hline 15 & 154 & 115 & 100 & 154 & 115 & 100 \\
\hline
\end{tabular}

For each tool material type, the combination of the varied process parameters and the experimental sequence were defined based on a design of experiments (DOE) with three levels, central point and five replicates (Fig. 1). It must be noted that the fixed parameters and the ranges of the variable ones can be dissimilar for the different materials; this solution was used in order to test suitable technological windows for each combination of materials. 
The combination of the variable parameters resulted into 15 different EDM working conditions (Technologies), 75 micro-holes for each combination electrode-workpiece and a total amount of 450 micro-holes.

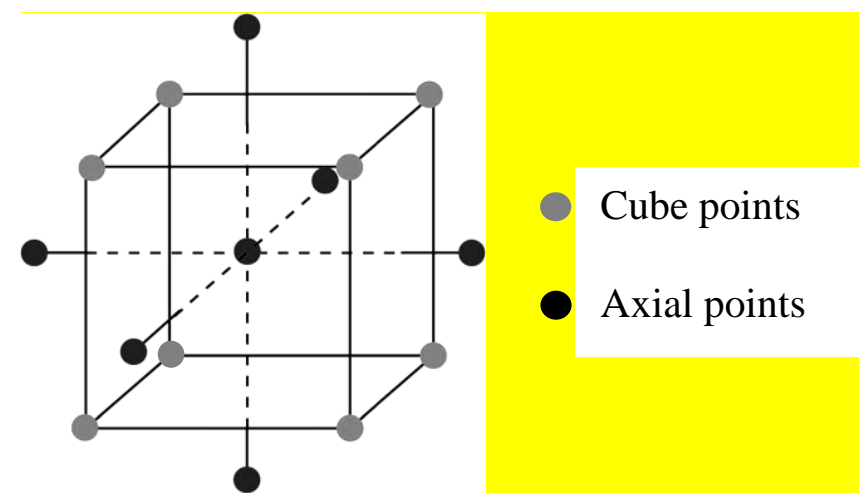

Figure 1. Scheme of a factorial design with three levels and central point.

At the end of each hole, the electrode clamp was moved to a specific reference point in order to measure the electrode wear by an electrode touching operation. The frontal tool wear was calculated as difference between the initial and the final length of the electrode. At the end of each hole drilling, the electrode tip was cut using the wire EDM unit to restore the same initial conditions for all the tests.

\section{Evaluation of the process performance and the geometrical characteristics of the micro-holes}

Material Removal Rate (MRR) and Tool Wear Ratio (TWR) were assumed as performance indexes. MRR was calculated as the ratio between the material removed from the workpiece $\left(\mathrm{MR}_{\text {workpiece }}\right.$, estimated as the frustum of cone volume) and the machining time recorded by the EDM system (Eq. 1).

$M R R=\frac{M R_{\text {workpiece }}}{t}=\frac{\pi h\left(D_{\text {top }}^{2}+D_{\text {top }} D_{\text {bottom }}+D_{\text {bottom }}^{2}\right)}{12 t}$

where $\mathrm{h}$ is the thickness of the plate, $D_{\text {top }}$ and $D_{\text {bottom }}$ are respectively the top and bottom diameters of the hole measured by an optical measuring microscope at a magnification of $100 \mathrm{X}$ and $t$ is the machining time recorded by the EDM system.

TWR was calculated as ratio between the material removed from the electrode $\left(\mathrm{MR}_{\mathrm{tool}}\right)$ and the material removed from the workpiece, as given in Eq. 2. 
$T W R=\frac{M R_{\text {tool }}}{M R_{\text {workpiece }}}$

The material removed from the tool is calculated as the volume of the tube having diameters equal to the nominal inner and outer electrode diameters $\left(D_{\text {int }}\right.$ and $\left.D_{\text {ext }}\right)$ and height equal to the measured tool wear $\left(h_{t}\right)$, as in Eq. 3.

$M R_{\text {tool }}=\frac{\pi h_{t}\left(D_{\text {ext }}^{2}-\mathrm{D}_{\mathrm{int}}^{2}\right)}{4}$

The geometrical characteristics of micro-holes were evaluated by taking into account Diametral Overcut (DOC) and Taper Rate (TR), as in Eq. 4-5.

$D O C=100 * \frac{D_{t o p}-\mathrm{D}_{e x t}}{\mathrm{D}_{e x t}}$

$T R=\frac{D_{\text {top }}-\mathrm{D}_{\text {bottom }}}{\mathrm{h}}$

\section{Definition of the Material-Technology Indexes}

Some specific Material-Technology Indexes (MTI) were proposed in order to summarize all the working conditions in terms of workpiece material, tool material and EDM process parameters. Based on previous results presented in [17], the performance and the geometrical characteristics of the micro holes are assumed to be directly proportional to peak current, voltage and frequency of the discharge. Besides, the coefficients of determination of these indexes with the EDM process performance and the geometrical characteristics were investigated.

The main effects plot of all the main characteristics affecting MRR is reported in Fig. 2. Y axis reports the mean value of MRR obtained as the average of all the executed experiments, with only one fixed parameter value (means at each level of a factor). MRR is directly proportional to the thermal conductivity of both electrodes (workpiece and tool) and is indirectly proportional to both electrodes melting temperature and electrical resistivity. 


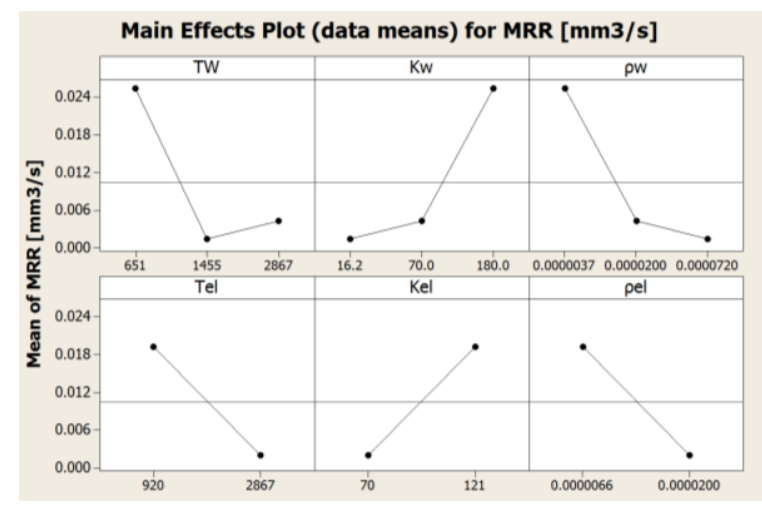

Figure 2. Main effects plot for MRR.

According to these remarks, the following MTI was elaborated:

$\operatorname{MTI}_{M R R}=\frac{I * V * F * k_{w} * k_{e l}}{T_{w} * \rho_{w} * T_{e l} * \rho_{e l}}$

When the thermal conductivity is high, the heat coming from the discharge is much more easily transferred to the workpiece, that result easier to be machined. When the melting point is low, the workpiece material results easier to be melted and therefore machining time is lower. Fig. 3 shows MRR as a function of the MT index: a parabolic trend with a very satisfactory coefficient of determination was obtained.

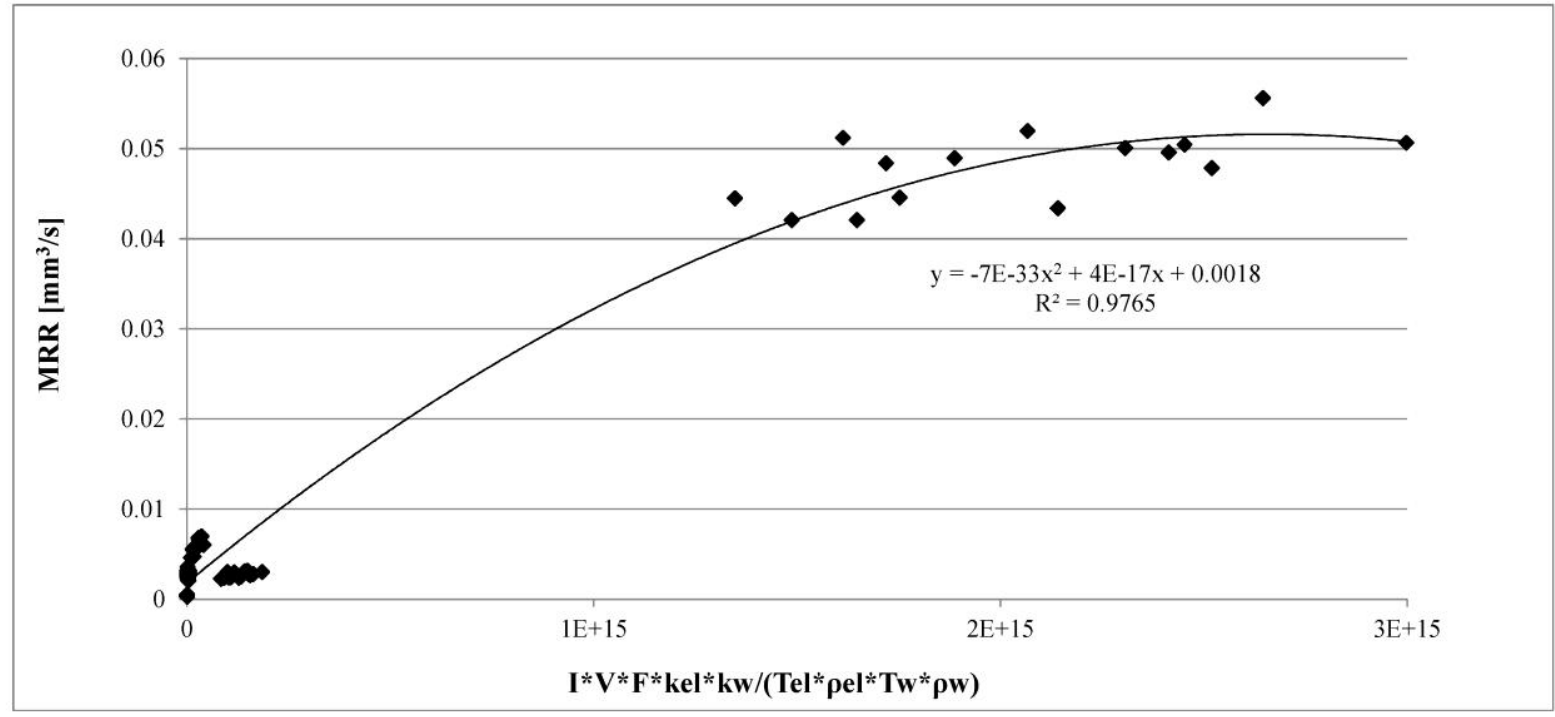

Figure 3. MRR as a function of MTI. 
The main effects plot for TWR is reported in Fig. 4. It is possible to observe that the TWR is directly proportional to $T w / T e l$ and $\rho w / \rho e l$ ratios and inversely proportional to $\mathrm{kel} / \mathrm{kw}$ ratio.

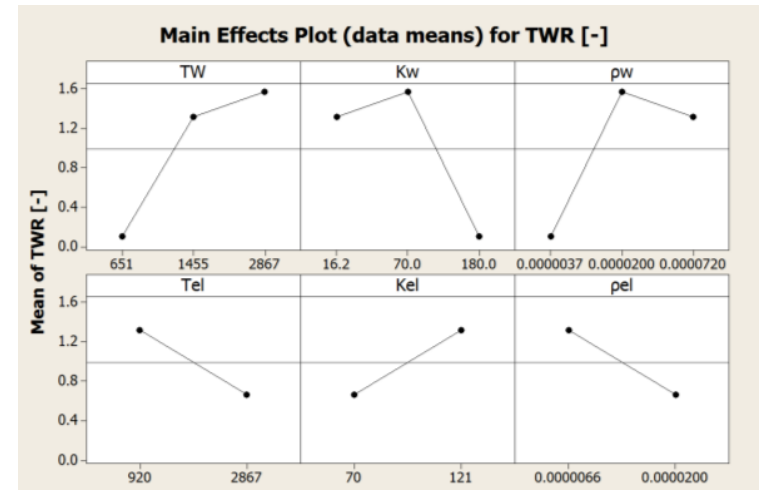

Figure 4. Main effects plot for TWR.

Based on this observations, the MTI for TWR was elaborated and reported in Eq. 7. Fig. 5 shows the trend of TWR by varying the index. The coefficient of determination is lower than the one obtained for MRR, but still acceptable.

$\operatorname{MTI}_{T W R}=\frac{I * V * F * T_{w} * \rho_{w} * k_{e l}}{T_{e l} * \rho_{e l} * k_{w}}$

As it is pointed out in the figure, when tungsten carbide is drilled using brass electrode, TWR assumes the highest values with respect to the values obtained in all the other cases. This explains the low value of the coefficient of determination. 


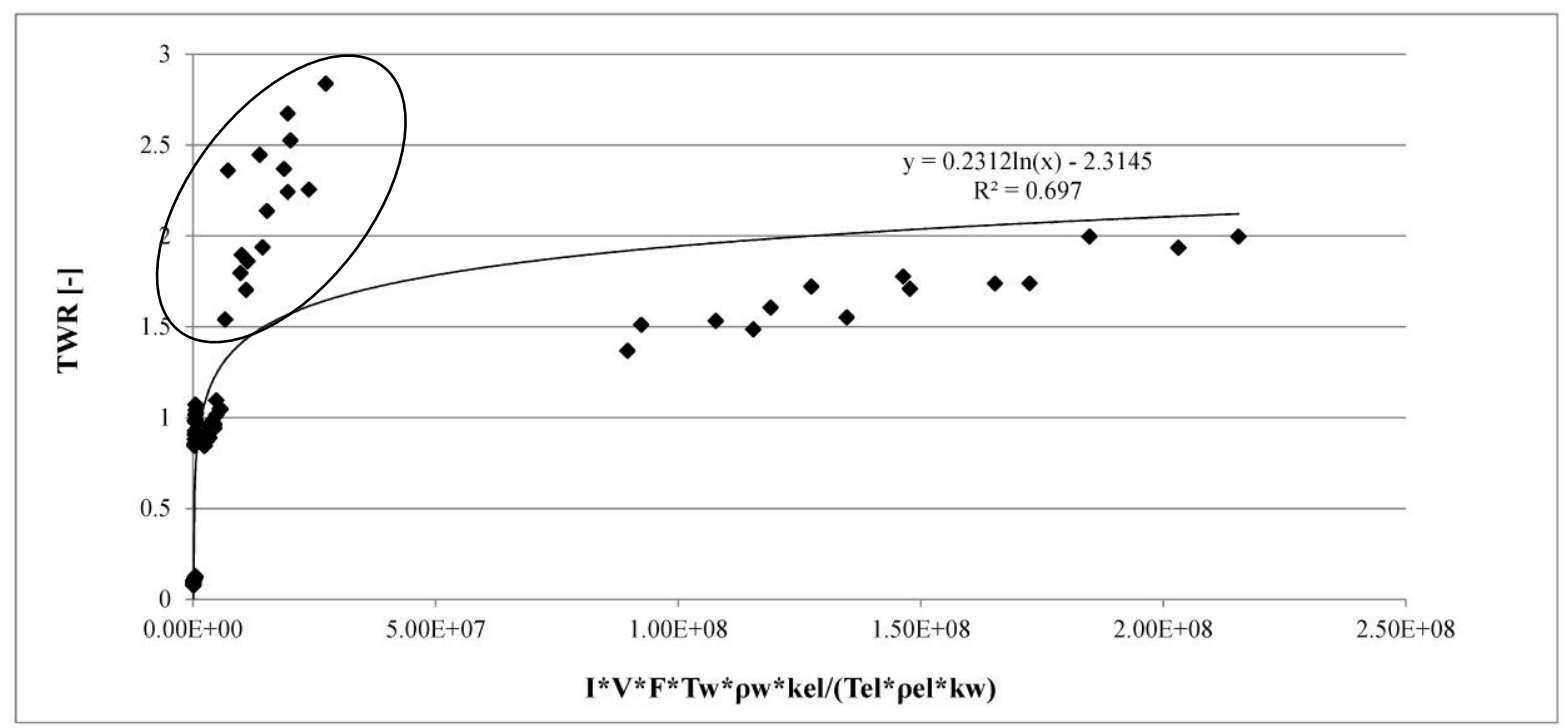

Figure 5. TWR as a function of MTI.

In order to obtain an acceptable value of the correlation coefficient, electrode wear was taken into account, modifying MTI index that becomes (Figure 6):

$M T I_{\text {wear }}=\frac{I * V^{*} F^{*} T_{w} * \rho_{w} *\left(k_{e l}\right)^{\wedge}(1 / 4)}{T_{e l} * \rho_{e l} *\left(k_{w}\right)^{\wedge}(1 / 2)}$

With respect to TWR, the electrode wear is a parameter independent from the geometrical characteristics of the hole and this permits to obtain a significate improvement in the fitting curve.

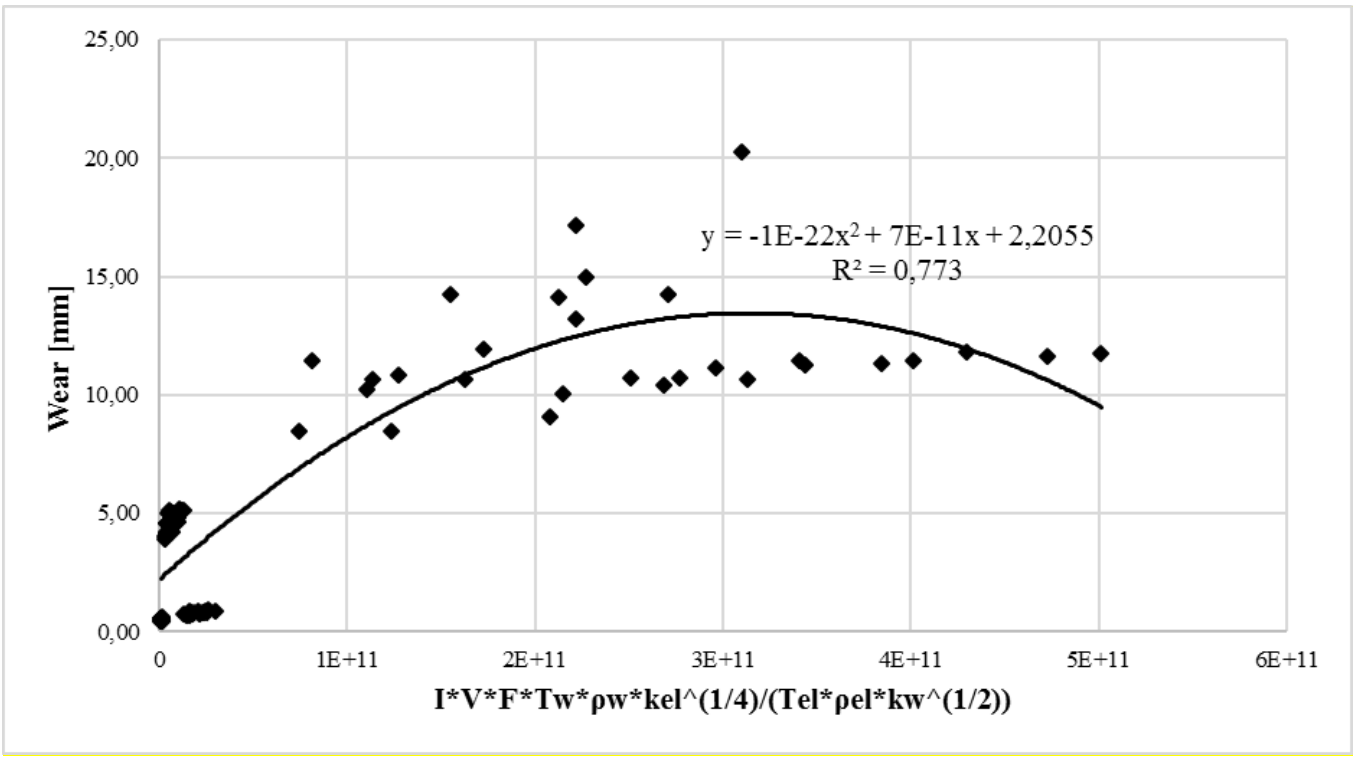

Figure 6. Electrode wear as a function of MTI. 
The main effects plot for DOC is shown in Fig. 7. These results can be explained considering a connection with machining time: when the removal of material occurs in a shorter time, overcut increases. MRR increases and machining time decreases for workpiece material having lower melting temperature. Moreover, decreasing the electrical resistivity and increasing the thermal conductivity of the tool, MRR and consequently DOC increases.

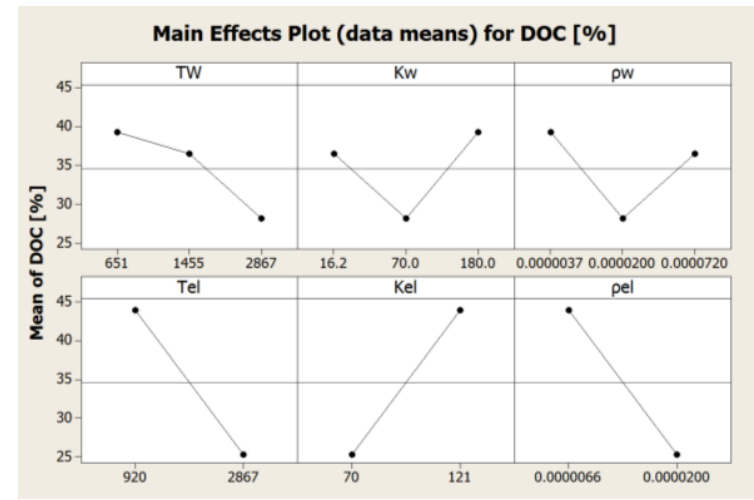

Figure 7. Main effects plot for DOC.

In this case, the influence of workpiece thermal and electrical properties is not clearly defined; then, these characteristics are not included in the index expressed by Eq. 9. The trend of DOC as a function of its index (Fig. 8) is fitted by a logarithmic law.

$M T I_{D O C}=\frac{I * V * F * k_{e l}}{T_{e l} * \rho_{e l} * T_{w}}$ 


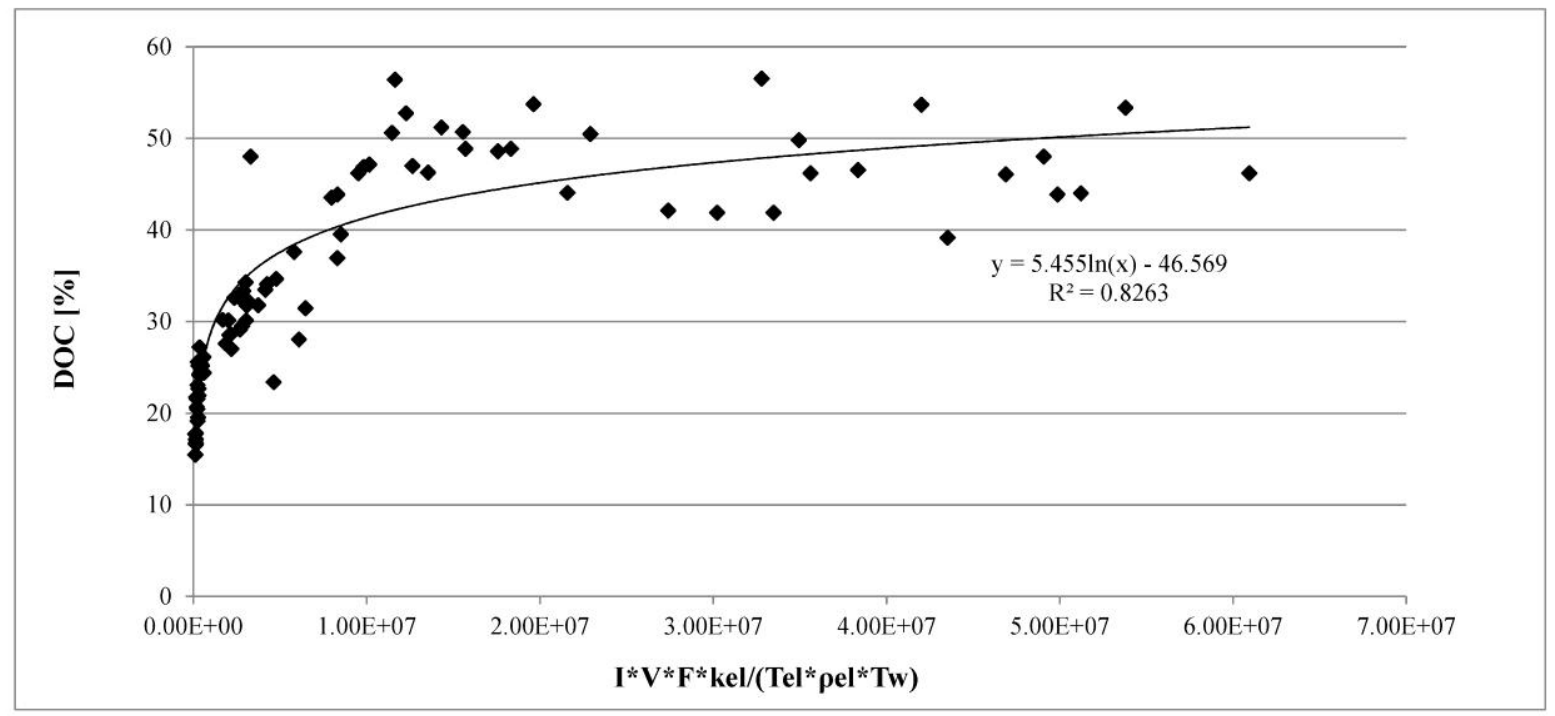

Figure 8. DOC as a function of MTI.

The main effects plot for TR is shown in Fig. 9; in this case the effect of workpiece melting temperature is not clearly defined. The characteristics of the tool affect TR in the same way of the other indicators.

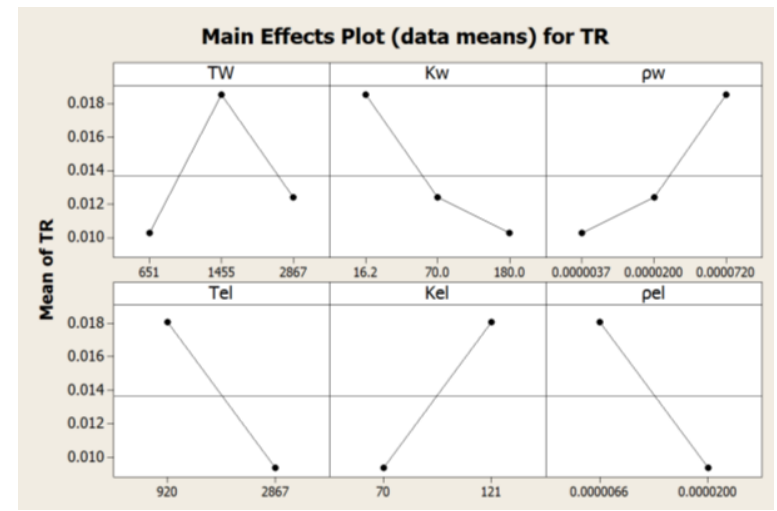

Figure 9. Main effects plot for TR.

The electrical and thermal characteristics of the workpiece influence TR in the opposite way with respect to MRR: the taper rate becomes worse when MRR decreases. The MTI of TR is defined in Eq. 10 and shown in Fig. 10.

$\operatorname{MTI}_{T R}=\frac{I * V * F * \rho_{w} * k_{e l}}{T_{e l} * \rho_{e l} * k_{w}}$ 


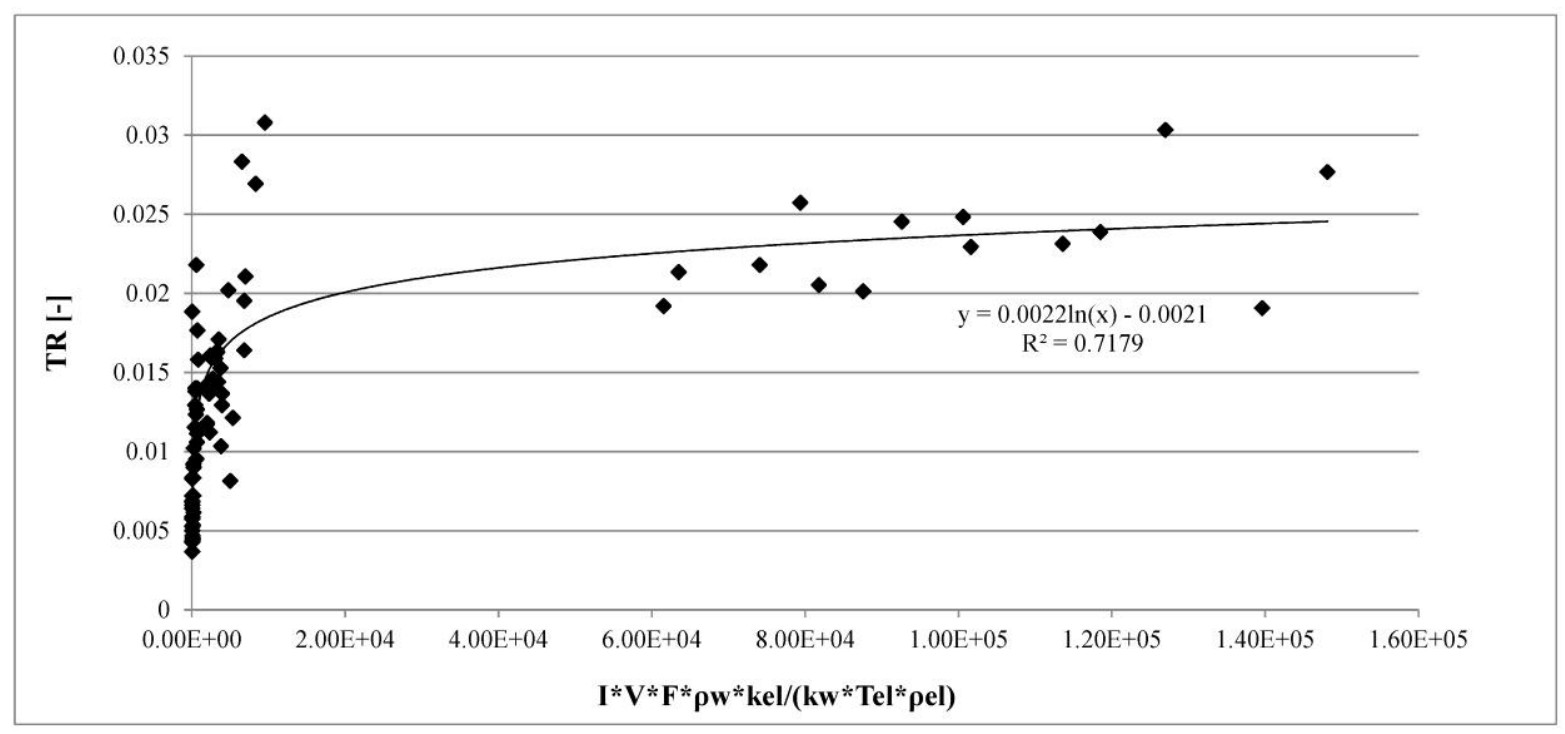

Figure 10. TR as a function of MTI.

\section{Surface integrity analysis}

The properties of workpiece have effect not only on the performance of micromachining but also on the micro hole surface. In order to analyse the surface integrity, SEM images of the internal surface of stainless steel, tungsten carbide and aluminium workpiece, obtained using the two electrode materials, were taken.

Figures 11-13 show SEM images at 2300X for low values of process parameters, using tungsten carbide (left side) and brass (right side) as electrode, for stainless steel, tungsten carbide and aluminium as workpiece.

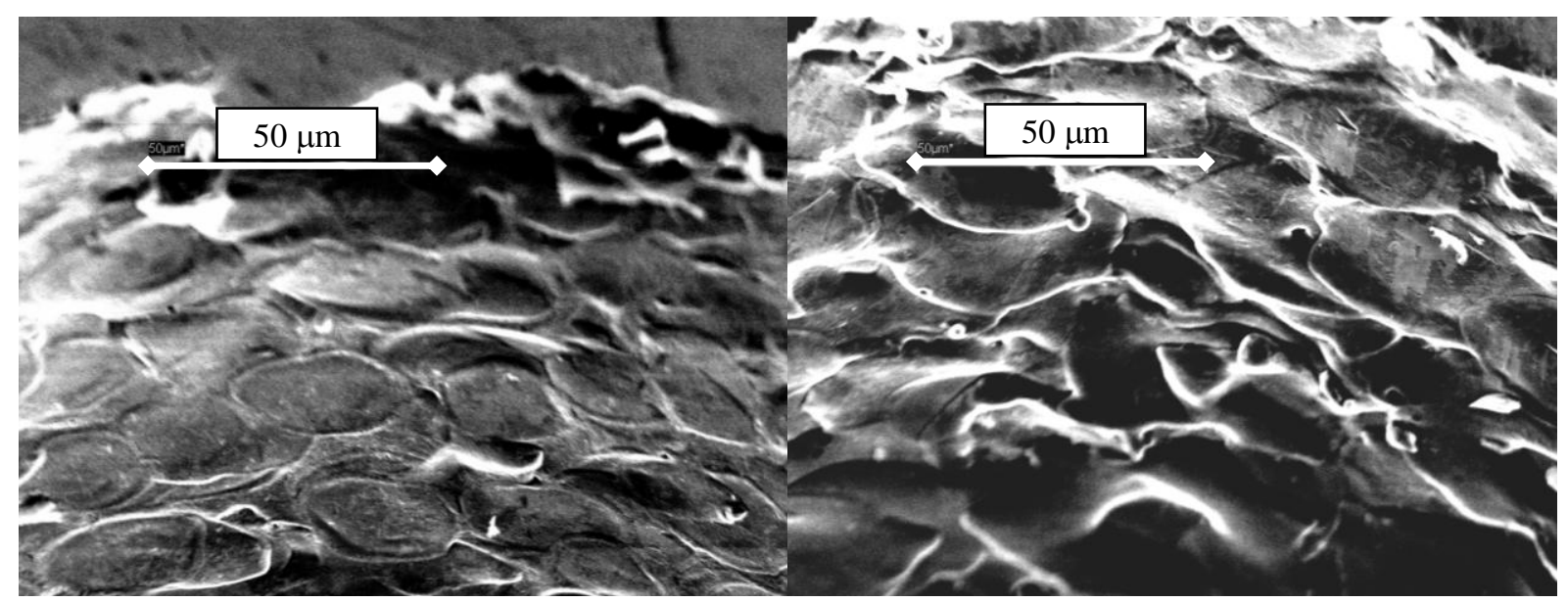

Figure 11. SEM images of micro holes on SS obtained using TC electrode (left side) and brass electrode (right side). 


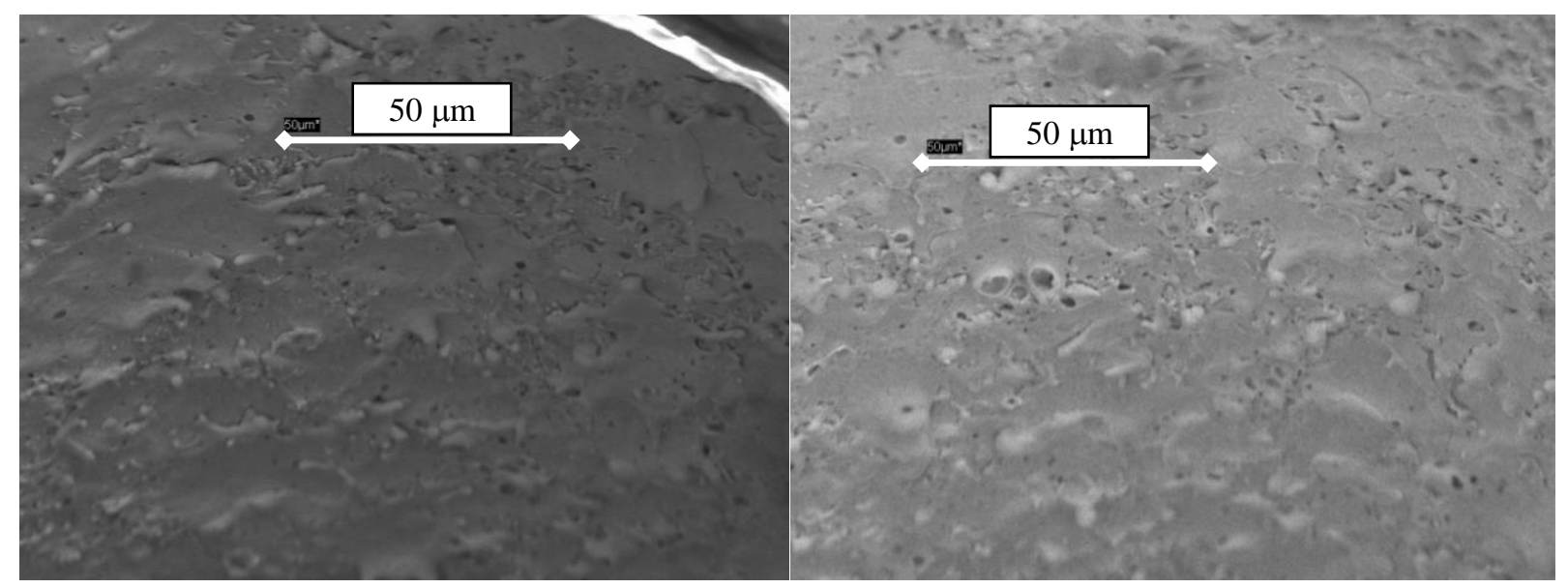

Figure 12. SEM images of micro holes on tungsten carbide obtained using TC electrode (left side) and brass electrode (right side).

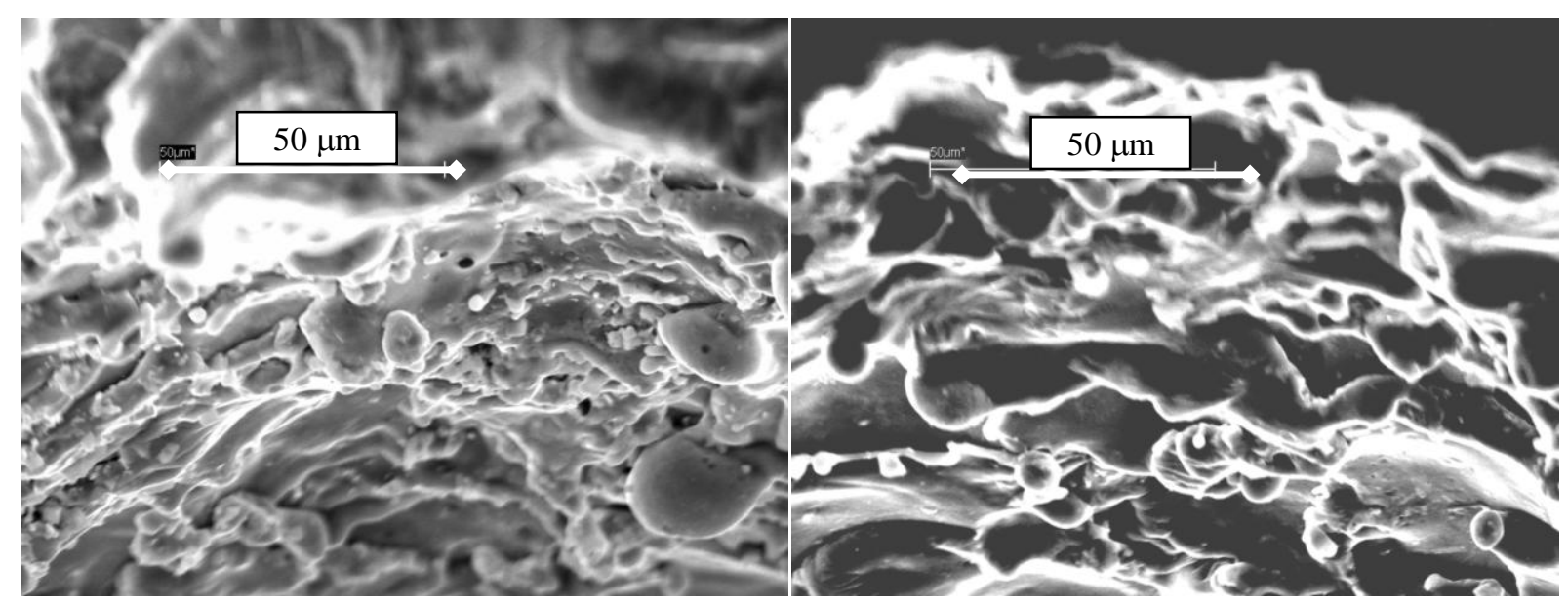

Figure 13. SEM images of micro holes on aluminium obtained using TC electrode (left side) and brass electrode (right side).

When stainless steel is machined, the EDM typical craters are evident; moreover, the use of brass electrode gives rise to a more indented surface while the use of TC results in a smoother surface. The internal surface of the TC workpiece is completely different and no significant differences can be observed by varying the electrode material. Concerning the surface of the aluminium workpiece, a large amount of resolidified material can be observed, especially when brass electrode is used.

A surface roughness analysis was carried out on the hole surfaces along the axial direction. The measurements were executed using a "Form Talysurf S21 PGI 420 (Taylor Hobson)" system with interferometric sensor. Table 5 reports the roughness values $(\mathrm{Ra})$ of Stainless Steel, aluminium and Tungsten carbide using two materials electrode at two 
different conditions in term of energy discharge. As a general remark, tungsten carbide electrode and low energy discharge give rise to lowest roughness values. As regards the workpiece materials, aluminum showed the worst surface roughness.

Table 5. Ra $[\mu \mathrm{m}]$ of the internal surface of micro holes varying process parameters and workpiece/electrode materials

\begin{tabular}{|l|c|c|c|c|}
\hline Electrode & \multicolumn{2}{|c|}{ Tungsten Carbide } & Low & High \\
\hline Energy discharge & Low & High & 0.567 & 0.659 \\
\hline Stainless Steel & 0.233 & 1.098 & 4.769 & 7.785 \\
\hline Aluminium & 3.938 & 4.202 & 1.621 & 1.805 \\
\hline Tungsten Carbide & 0.987 & 1.273 & & \\
\hline
\end{tabular}

\section{Conclusions}

The MT indexes, taking into account EDM process parameters, electrical and thermal properties of both workpiece and electrode materials, were proposed for the evaluation of MRR, TWR, DOC and TR. The effects of these indexes on the process and geometrical performance were finally analyzed and summarized by means of proper fitting equations. As a general remark, all the defined indexes resulted to be affected by the electrode properties, while not all the workpiece characteristics seem to have a significant effect for the index elaboration. The electrical process parameters have the same kind of influence on the performance indexes; a same consideration can be done for the electrode properties. Based on this considerations, the maximum MRR can be obtained penalizing the other indexes. The workpiece properties instead, have effect on the indexes in different ways. Then, once an objective function is selected, the best conditions can be estimated. The results are useful in the industrial field for the selection of the suitable micro-EDM parameters and for the prediction of the process and product performance.

\section{References}

[1] Sundaram MM, Pavalarajan GB, Rajurkar KP. A Study on Process Parameters of Ultrasonic Assisted Micro EDM Based on Taguchi Method. JMEPEG 2008;17:210-215.

[2] Weule $\mathrm{H}$, et al. International state of the art of micro production technology. Production Engineering 2004;XI(1):29-36.

[3] Diver C., et al. Micro-EDM drilling of tapered holes for industrial applications. J. Mat. Proc. Tech. 
2004;149:293-303.

[4] Sona SM, Limb HS, Kumarb AS, Rahmanb M. Influences of pulsed power condition on the machining properties in micro EDM. Journal of Materials Processing Technology 2007;190:73-76.

[5] Diver C, Atkinson J, Helmi HJ, Li L. Micro-EDM drilling of tapered holes for industrial applications. J Mater process Technol 2004;149:293-303.

[6] Pradhan BB, Masanta M, Sarkar BR, Bhattacharyya B. Investigation of electro-discharge micro-machining of titanium super alloy. International Journal Advanced Manufacturing Technology 2009;41:1094-1106.

[7] Kuppan P, Rajadurai A, Narayanan S. Influence of EDM process parameters in deep hole drilling of Inconel 718. International Journal Advanced Manufacturing Technology 2008;38:74-84.

[8] Kiyak M, et al. Effects of discharge energy density on wear rate and surface roughness in EDM. Int. J. Adv. Manuf. Tech. 2015;79:513-518.

[9] Fonda P, et al. A fundamental study on Ti-6Al-4V's thermal and electrical properties and their relation to EDM productivity. J. of Mat. Proc. Tech. 2008;202:583-589.

[10] Muhardika M, et al. A new approach on the determination of ease of machining by EDM processes. Int. J. Mach. Tool and Manuf. 2008;48:746-760.

[11] Tsai YY, Masuzawa T. An index to evaluate the wear resistance of the electrode in micro-EDM. J. of Mat. Proc. Tech. 2004;149:304-309.

[12] Marafona JD, et al. Influence of workpiece hardness on EDM performance. Int J. Mach. Tool. 2009;49:744748.

[13] Li J, et al. Influence of Material Microstructure on Micro EDM. Appl. Mech. \& Mat. 2012;130:927-930.

[14] D’Urso G, Maccarini G, Ravasio C. Process performance of micro-EDM drilling of stainless steel. International Journal of Advanced Manufacturing Technology 2014;72 (9): 1287-1298.

[15] Moses MD, Jahan MP. Micro-EDM machinability of difficult-to-cut Ti-6Al-4V against soft brass. Int J Adv Manuf Technol 2015;81:1345-1361.

[16] D’Urso G, Maccarini G, Quarto M, Ravasio C. Investigation on power discharge in micro-EDM stainless steel drilling using different electrodes. Journal of Mechanical Science and Technology 2015;29(10):43414349.

[17] D’Urso G, Maccarini G, Ravasio C. Influence of electrode material in micro-EDM drilling of stainless steel and tungsten carbide. Int J Adv Manuf Technol, DOI 10.1007/s00170-015-7010-9. 
[18] Liu K, Lauwers B, Reynaerts D. Process capabilities of Micro-EDM and its applications. Int J Adv Manuf Technol, DOI 10.1007/s00170-009-2056-1. 